\title{
0398 COST EFFECTIVENESS ANALYSIS OF PLAYGROUND SURFACING AT PREVENTING ARM FRACTURES IN A RANDOMISED STUDY
}

L Rothman*, A Macpherson, A Howard Correspondence: Hospital for Sick Children, 555 University Avenue, Toronto, Ontario, M5G 1X8, Canada

\subsection{6/ip.2010.029215.398}

Background Upper extremity fractures resulting from playground falls are commonly seen in emergency departments. A 2-year randomised surfacing trial conducted in 19 schools in Toronto, Canada, found that the risk of fracture from playground equipment falls was 4.9 times lower in schools with granite sand playground surfacing $(0.019 / 1000$ student months $)$ compared to engineered wood fibre (EWF; 0.094/1000 student months). A subsequent analysis was conducted to determine the cost effectiveness of granite sand in reducing arm fractures in school playgrounds.

Methods The Ontario Case Costing Initiative provided hospital costs. Physician service costs were obtained from the Ontario Health Insurance Schedule of Benefits. The Toronto District School Board provided costs of installation and maintenance for each surface type. Total cost was calculated per 1000 student months, by combining treatment costs with surfacing costs. Cost saved per fracture prevented was calculated.

Results The total cost of surfacing and injury was $\$ 890.61$ for sand and $\$ 949.00$ per 1000 student months for EWF. Although the cost of surfacing was greater for sand ( $\$ 887.14$ vs $\$ 841.83$ for EWF), the cost per injury was substantially lower for those injured on sand ( $\$ 3.47$ vs $\$ 107.17$ for EWF). Sand surfacing resulted in $0.08 / 1000$ fractures prevented. The total cost saving per fracture prevented with sand was $\$ 779.00$.

Discussion Both healthcare and schools are publicly funded in Toronto through the provincial government. The installation of sand surfacing in school playgrounds would generate a cost savings to the public, while substantially reducing the number of arm fractures. 